\title{
Incorporation of partially purified hen egg white lysozyme into zein films for antimicrobial food packaging
}

\author{
Çiğdem Mecitoğlu ${ }^{\mathrm{b}}$, Ahmet Yemenicioğlu ${ }^{\mathrm{a}, *}$, Alper Arslanoğlu ${ }^{\mathrm{c}}$, Zehra Seda Elmac1 ${ }^{\mathrm{c}}$, \\ Figen Korel ${ }^{\text {a }}$, Ali Emrah Çetin ${ }^{\mathrm{d}}$ \\ ${ }^{a}$ Department of Food Engineering, Faculty of Engineering, Izmir Institute of Technology 35430, Gülbahçe Köyü, Urla, Izmir, Turkey \\ ${ }^{\mathrm{b}}$ Biotechnology and Bioengineering Program, Izmir Institute of Technology 35430, Gülbahçe Köyü, Urla, Izmir, Turkey \\ ${ }^{\mathrm{c}}$ Department of Biology, Faculty of Science, Izmir Institute of Technology 35430, Gülbahçe Köyü, Urla, Izmir, Turkey \\ ${ }^{\mathrm{d}}$ Department of Chemical Engineering, Faculty of Engineering, Izmir Institute of Technology 35430, Gülbahçe Köyü, Urla, Izmir, Turkey
}

Received 3 February 2005

\begin{abstract}
Lysozyme, partially purified from hen egg white by precipitation of non-enzyme protein with ethanol and lyophilized after dialysis, was incorporated into zein films. The recovery and specific activity of the enzyme after partial purification varied between $45 \%$ and $72 \%$ and 2173 and $3448 \mathrm{U} / \mathrm{mg}$, whereas the activity of the lyophilized enzyme varied between 2900 and $3351 \mathrm{U} / \mathrm{mg}$. The partially purified enzyme was very stable and lost almost no activity in lyophilized form or in zein films stored at -18 and $4{ }^{\circ} \mathrm{C}$ for up to 8 and 4 months, respectively. During partial purification and in zein film preparation, ethanol treatment caused $123-137 \%$ and $132-315 \%$ activation of the enzyme, respectively. In zein films incorporated with $187-1318 \mathrm{U} / \mathrm{cm}^{2}\left(63-455 \mu \mathrm{g} / \mathrm{cm}^{2}\right)$ lysozyme, the release rates at $4{ }^{\circ} \mathrm{C}$, changed between 7 and $29 \mathrm{U} / \mathrm{cm}^{2} / \mathrm{min}$, increased at high lysozyme concentrations. Zein films incorporated with partially purified lysozyme showed antimicrobial effect on Bacillus subtilis and Lactobacillus plantarum. By the addition of disodium EDTA, the films also became effective on Escherichia coli. The results of this study showed that the partially purified lysozyme may be used in antimicrobial packaging to increase food safety.
\end{abstract}

(c) 2005 Elsevier Ltd. All rights reserved.

Keywords: Lysozyme; Partial purification; Edible films; Incorporation; Antimicrobial packaging

\section{Introduction}

The increased demand on easily prepared minimally processed fresh produce and the related increase in foodborne microbial outbreaks (De Roever, 1998) have intensified the research on antimicrobial packaging technologies (Suppakul, Miltz, Sonneveld, \& Bigger, 2003). The antimicrobial packaging is conducted by (1) the addition of antimicrobial containing sachets or pads into food packages; (2) the coating, immobilization or direct incorporation of antimicrobials into food packaging

\footnotetext{
* Corresponding author. Tel.: +90 (232) 7506292; fax: +90 (232) 7506196.

E-mail address: ahmetyemenicioglu@iyte.edu.tr (A. Yemenicioğlu).
}

materials or (3) the use of packaging materials that are inherently antimicrobial (Appendini \& Hotchkiss, 2002).

Different chemicals such as organic or inorganic acids, metals, alcohols, ammonium compounds or amines can be incorporated into packaging materials as antimicrobials (Appendini \& Hotchkiss, 2002; Suppakul et al., 2003). However, because of the health concerns of the consumers, producers are now highly interested in the use of biopreservatives in antimicrobial packaging. The biopreservatives suggested for antimicrobial packaging include bacteriocins such as nisin, pediocin and lacticin and antimicrobial enzymes such as lysozyme, lactoperoxidase, chitinase and glucose oxidase (Labuza \& Breene, 1989; Suppakul et al., 2003). Because of the environmental concerns and technological problems 
such as denaturing effects of thermal polymer processing methods, extrusion and injection molding, the incorporation of biopreservatives into biodegradable films is more suitable than their incorporation into plastic films (Appendini \& Hotchkiss, 2002; Han, 2000; Suppakul et al., 2003). Most of the biodegradable films are edible and their film formation occurs under mild conditions. Different edible films incorporated with biopreservatives include films from cellulose derivatives, carrageenan, alginate, and whey proteins (Cha, Choi, Chinnan, \& Park, 2002; Han, 2000; Quintavalla \& Vicini, 2002; Suppakul et al., 2003). Recently, a particular interest has also been focused on the incorporation of different biopreservatives such as nisin and lysozyme (Dawson, Hoffman, \& Han, 2000; Hoffman, Han, \& Dawson, 2001; Janes, Kooshesh, \& Johnson, 2002; Padgett, Han, \& Dawson, 1998; Teerakarn, Hirt, Acton, Rieck, \& Dawson, 2002) and antioxidants such as BHA (Herald, Hachmeister, Huang, \& Bowers, 1996) into zein films. Zein may be applied as food coating or its pre-cast films may be used for wrapping of foods (Herald et al., 1996; Janes et al., 2002). Recently, the pre-cast zein films have also been used successfully for the modified atmosphere packaging of vegetables (Rakotonirainy, Wang, \& Padua, 2001).

Lysozyme is one of the most frequently used biopreservatives in antimicrobial packaging (Han, 2000; Quintavalla \& Vicini, 2002). This enzyme shows antimicrobial activity mainly on gram-positive bacteria by splitting the bonds between $N$-acetylmuramic acid and $N$-acetylglucosamine of the peptidoglycan in their cell walls. Because of their protective outer membrane surrounding the peptidoglycan layer, lysozyme does not show antibacterial activity against gram-negative bacteria. However, when it is combined with EDTA the outer membranes of gram-negative bacteria are destabilized by this agent and the antimicrobial spectrum of lysozyme increases significantly (Branen \& Davidson, 2004; Padgett et al., 1998). In studies related to antimicrobial films, most of the workers used commercial lysozyme obtained by the classical repeated salt crystallization method which may require a week until the enzyme is obtained with sufficient purity (Chang, Yang, $\&$ Chang, 2000). The commonly used commercial lysozymes are quite pure. They are reported to contain only 1-6\% (w/w) protein impurities (Judge, Forsythe, \& Pusey, 1998), and they have a very high enzyme activity (between 20,000 and 100,000 U/mg). However, for the application of lysozyme in food industry, the use of cheaper partially purified lysozyme preparations obtained by some faster methods may be economically more feasible. For this reason, some fast partial purification procedures have recently been developed based on heat induced precipitation of non-lysozyme protein impurities in presence of reductants (Chang et al., 2000) or selective precipitation of lysozyme with anionic sur- factants (Shin, Rodil, \& Vera, 2003). In this study, to develop a more applicable active packaging system for food industry, the partially purified lysozyme produced by ethanol precipitation of non-lysozyme proteins (Jiang, Wang, Chang, \& Chang, 2001) was incorporated into zein films. Since the purity of lysozyme may affect its stability, interactions, release rates or antimicrobial activity, we studied the release rates of lysozyme from zein films at cold storage temperature $\left(4^{\circ} \mathrm{C}\right)$, investigated the effects of film making and cold storage on lysozyme activity, and tested the antimicrobial effects of the obtained films on different bacteria.

\section{Materials and methods}

\subsection{Materials}

Corn zein, Micrococcus lysodeikticus and dialysis tubes $(12,000 \mathrm{MW}$, prepared as described in the product manual) were obtained from Sigma Chem. Co. (St. Louis, MO, USA). Glycerol was purchased from Merck (Darmstadt, Germany). Disodium EDTA was purchased form Riedel-de haën (Sigma-Aldrich Laborchemikalien, Seelze, Germany). Fresh hen eggs used in production of lysozyme were obtained from a supermarket in İzmir (Turkey).

\subsection{Film making}

Zein films were produced as described in Padgett et al. (1998). Briefly, $1.4 \mathrm{~g}$ corn zein was dissolved with $8.1 \mathrm{~mL}$ of ethanol $(97 \%)$ by mixing slowly with a magnetic stirrer for $25 \mathrm{~min}$. $0.39 \mathrm{~mL}$ glycerol was then added to the medium and the temperature of the mixture was increased until it started to boil. The mixing was then ceased and the film solution was boiled for 5 min. After cooling to room temperature, different amounts of lysozyme and/or disodium EDTA were added to the mixture to achieve $187-1524 \mathrm{U} / \mathrm{cm}^{2}$ (63$530 \mu \mathrm{g} / \mathrm{cm}^{2}$ ) and $180 \mu \mathrm{g} / \mathrm{cm}^{2}$ final concentrations in dried films, respectively. The mixture was further stirred for $25 \mathrm{~min}$ and $4.3 \mathrm{~g}$ of it was spread evenly onto a $8.5 \times 8.5 \mathrm{~cm}$ glass plate, previously cleaned with ethanol. The plates were placed in an incubator (Memmert, 108 L, Model BE 500, Germany) and the films were dried at room temperature for $24 \mathrm{~h}$ by keeping the incubator door half open. After drying, the films were peeled from the glass plates carefully and $6 \times 6 \mathrm{~cm}$ pieces cut from the middle of films were used in all tests. The average thicknesses of the films obtained by this procedure changed between 0.139 and $0.142 \mathrm{~mm}$ for control, lysozyme incorporated or lysozyme and disodium EDTA incorporated zein films (minimum 20 measurements were conducted at different points of each kind of film with a micrometer). 


\subsection{Production of partially purified lysozyme}

Lysozyme was produced by slightly modifying the partial purification step given in Jiang et al. (2001). Briefly, the egg whites separated carefully without disturbing the egg yolks were first diluted 3-fold with $0.05 \mathrm{M} \mathrm{NaCl}$ solution. To precipitate the egg white proteins other than the lysozyme, the $\mathrm{pH}$ of this mixture was set to 4.0 by carefully adding several drops of $1 \mathrm{~N}$ acetic acid and it was diluted with equal volume of $60 \%(\mathrm{v} / \mathrm{v})$ ethanol. After $6 \mathrm{~h}$ incubation at room temperature in presence of $30 \%$ ethanol, the mixture was centrifuged at $15,000 \mathrm{~g}$ for $15 \mathrm{~min}$ at $4{ }^{\circ} \mathrm{C}$ and the precipitate was discarded. The supernatant containing lysozyme was first dialyzed for $21 \mathrm{~h}$ at $4{ }^{\circ} \mathrm{C}$ by three changes of $2000 \mathrm{~mL}$ distilled water and then lyophilized by using a freeze drier (Labconco, FreeZone, 6 liter, Kansas City, MO, USA) working between -44 and $-47^{\circ} \mathrm{C}$ collector temperature and $50 \times 10^{-3}$ and $100 \times 10^{-3}$ mbar vacuum. The sample container volume was two to three times the sample volume. The lyophilized enzymes used in film making were stored at $-18^{\circ} \mathrm{C}$ and their activities were determined as $\mathrm{U} / \mathrm{mg}$ before each film preparation.

\subsection{Protein content}

Protein content was determined according to Lowry procedure by using bovine serum albumin as standard (Harris, 1987).

\subsection{Lysozyme activity}

The activity of lysozyme was determined spectrophotometrically at $660 \mathrm{~nm}$ by using a Shimadzu (Model 2450 , Japan) spectrophotometer equipped with a constant temperature cell holder working at $30^{\circ} \mathrm{C}$. The reaction mixture was prepared by mixing $2.3 \mathrm{~mL}$ M. lysodeikticus cell suspension (at $30^{\circ} \mathrm{C}$ ) prepared $0.26 \mathrm{mg} / \mathrm{mL}$ in $0.05 \mathrm{M}, \mathrm{pH} 7.0 \mathrm{Na}$-phosphate buffer and $0.2 \mathrm{~mL}$ enzyme solution (incubated at $30^{\circ} \mathrm{C}$ for $5 \mathrm{~min}$ ). The reduction in absorbance was monitored for $5 \mathrm{~min}$ and enzyme activity was calculated from the slope of the initial linear portion of absorbance vs. time curve. The enzyme activity was expressed as unit or percent initial activity. One unit was 0.001 change in absorbance in $1 \mathrm{~min}$.

\subsection{Release tests}

The release tests were conducted in a refrigerated incubator (126 L, Sanyo Model MIR-153, Japan) at $4^{\circ} \mathrm{C}$. The films $(6 \times 6 \mathrm{~cm})$ were placed in glass petri dishes $(10 \mathrm{~mm}$ in diameter) containing $50 \mathrm{~mL}$ distilled water $\left(4^{\circ} \mathrm{C}\right)$. The petri dishes were then covered with nylon stretch films and their glass lids and incubated for $1800 \mathrm{~min}$ with continuous stirring at $200 \mathrm{rpm}$ with a magnetic stirrer ( $2 \mathrm{~cm}$ long teflon coated rod). The lysozyme activity released from films was monitored by taking $0.6 \mathrm{~mL}$ aliquots from the release test solution at different time intervals and conducting activity measurements for three times by using $0.2 \mathrm{~mL}$ of the taken aliquot in a single measurement. The activity was expressed as total units released per $\mathrm{cm}^{2}$ of the films $\left(\mathrm{U} / \mathrm{cm}^{2}\right)$ for a given time period. All calculations were corrected by considering the total activity removed during sampling. The monitoring of enzyme release was continued until the activity increase in release test solutions ended and a slight reduction in activity initiated. The release rates were calculated from the slopes of the best fit curves of initial portions of activity released vs. time curves as $\mathrm{U} / \mathrm{cm}^{2} / \mathrm{min}$. The total activity released from a film was determined by considering the peak points (maximum activity) in activity released vs. time curves. The percentage of activity recovered from a film in a release test was determined from the ratio of the total activity released and the incorporated activity, calculated by considering the activity and amount of partially purified lysozyme added to film making solutions.

\subsection{Determination of immobilized lysozyme activity retained in films}

In this study, no activity release was determined from the films at the end of release tests last for $1800 \mathrm{~min}$. Thus, the enzyme retained in zein films after release test was designated as immobilized enzyme. To determine the immobilized enzyme activity, the films $(6 \times 6 \mathrm{~cm})$ obtained from release tests for $1800 \mathrm{~min}$ were placed into glass petri dishes containing $25 \mathrm{~mL} M$. lysodeikticus solution $\left(\right.$ at $30^{\circ} \mathrm{C}$ ) prepared $0.26 \mathrm{mg} / \mathrm{mL}$ in $0.05 \mathrm{M}, \mathrm{pH}$ 7.0 Na-phosphate buffer. The petri dishes were kept in an incubator at $30^{\circ} \mathrm{C}$ and their contents' absorbance at $660 \mathrm{~nm}$ was monitored periodically. The lysozyme activity of the films were determined from the slopes of the initial linear portions of absorbance vs. time curve and given as $\mathrm{U} / \mathrm{cm}^{2}$ after multiplication of the obtained result by the factor of 10 . The factor was used to obtain comparable results with the measurements of standard reaction mixture of soluble enzyme that has 10 -fold smaller reaction volume.

\subsection{Stability of lysozyme activity}

The stability of the activity of partially purified lysozyme was determined in lyophilized form or in zein films. To determine the stability of lyophilized form, the activities of different batches of enzyme produced were monitored during storage at $-18^{\circ} \mathrm{C}$. In tests, the lyophilized enzyme preparations were dissolved in distilled water. For the determination of the stability of enzyme in films, $374 \mathrm{U} / \mathrm{cm}^{2}\left(112 \mu \mathrm{g} / \mathrm{cm}^{2}\right)$ lysozyme and 
$180 \mu \mathrm{g} / \mathrm{cm}^{2}$ disodium EDTA incorporated films were cold stored at $4{ }^{\circ} \mathrm{C}$. In certain time periods, the films $(6 \times 6 \mathrm{~cm})$ were placed into glass petri dishes containing $50 \mathrm{~mL}$ distilled water at $4{ }^{\circ} \mathrm{C}$ and stirred at $200 \mathrm{rpm}$ as described in the release tests. At the end of $1800 \mathrm{~min}$, a period that enzyme release ended and a slight decline was observed in activity, the films were removed from distilled water and the total enzyme activity in release test solution was determined. The activity was expressed as total units released per $\mathrm{cm}^{2}$ of the films.

\subsection{Test of film antimicrobial activity}

Test of antimicrobial activity was conducted by using Bacillus subtilis (ATCC 6633), Escherichia coli (ATCC 53868) and Lactobacillus plantarum (DSM 1954 ) as test microorganisms. The overnight cultures of B. subtilis and E. coli were prepared in nutrient broth whereas L. plantarum was grown in MRS broth. All incubations were conducted at $37^{\circ} \mathrm{C}$. For antimicrobial tests 20 discs $(0.9 \mathrm{~cm}$ in diameter) were prepared from $6 \times 6 \mathrm{~cm}$ films by a cork borer under aseptic conditions. The cutting was performed carefully to obtain samples from all film surface and 9 (3 for controls) of the obtained discs were selected randomly and used in antimicrobial tests. During tests, 3 discs were placed into each petri dish. For B. subtilis and E. coli, the discs were placed carefully onto petri dishes containing nutrient agar on which $0.1 \mathrm{~mL}$ culture was spread. For $L$. plantarum the same method was applied by using MRS agar instead of nutrient agar and spreading $0.2 \mathrm{~mL}$ culture. Also, after placing films, a second layer of MRS agar was poured onto these petri dishes. All petri dishes were incubated for $3-4$ days at $37^{\circ} \mathrm{C}$ and the area of the fully formed zones observed was determined by measuring the zone diameter with a caliper. The areas of partially formed zones, occurred mostly on one side of the discs, were not reported. However, the number of such zones and negative discs were noted.

\section{Results and discussion}

\subsection{Partially purified lysozyme}

The partial purification study in this work was based on the removal of egg white proteins other than the lysozyme by ethanol precipitation (Jiang et al., 2001). During precipitation, the $\mathrm{pH}$ of the medium was set close to the isoelectric point $(\mathrm{p} I)$ of the major egg white protein ovalbumin $(\mathrm{p} I=4.5)$. The purification fold and the recovery of lysozyme from different batches of hen egg whites were given in Table 1 for the different stages of the partial purification process (Table 1). The $\mathrm{pH}$ adjustment and the addition of ethanol caused the activation of the enzyme. Thus, the recovery of enzyme after $6 \mathrm{~h}$ incubation period changed between 123\% and 137\%. Jiang et al. (2001) applied this method with $8 \mathrm{~h}$ ethanol incubation period and without dialysis as a partial purification procedure before column chromatography. However, although these workers attributed the high recovery of lysozyme to the protective effect of ethanol they did not observe the activation of enzyme with the ethanol treatment. Our preliminary studies conducted by measuring the enzyme activity at $\mathrm{pH} 7.0$ following bringing extract $\mathrm{pH}$ to 4.0 showed that the $\mathrm{pH}$ adjustment applied during extraction did not cause any activation (results were not given). Thus, it is clear that the activation is related to the ethanol treatment. The effect of ethanol on lysozyme depends on its concentration (Bonincontro, De Francesco, Matzeu, Onori, \& Santucci, 1997; Liu, Bratko, Prausnitz, \& Blanch, 2004). For example, Bonincontro et al. (1997) reported that at very low ethanol concentrations at which mole fraction of ethanol in lysozyme solution is 0.06 , the $\alpha$-helix content of the enzyme increases. At higher mole fractions of ethanol (between 0.06 and 0.25 ) the $\alpha$-helix content approaches to that of its native form but the enzyme becomes more tightly folded. Liu et al. (2004) reported that ethanol concentrations between $0 \%$ and $20 \%(\mathrm{v} / \mathrm{v})$ enhance the lysozyme solution stability. It was hypothesized that the stabilization occurs as a result of the

Table 1

Partial purification of lysozyme from hen egg white

\begin{tabular}{|c|c|c|c|c|c|c|}
\hline Batch no. & Volume $(\mathrm{mL})$ & Total activity $(\mathrm{U})$ & Total protein $(\mathrm{mg})$ & Specific activity (U/mg) & Recovery (\%) & Purity (fold) \\
\hline \multicolumn{7}{|c|}{ Dilution of egg white 3-fold with $0.05 \mathrm{M} \mathrm{NaCl}$} \\
\hline 1 & 147 & $3,049,000$ & 7218 & 422 & 100 & 1 \\
\hline 2 & 147 & $3,256,000$ & 7696 & 423 & 100 & 1 \\
\hline 3 & 147 & $4,010,000$ & 7999 & 501 & 100 & 1 \\
\hline \multicolumn{7}{|c|}{$p H$ adjustment +6 incubation in presence of $30 \%$ ethanol } \\
\hline 1 & 250 & $4,167,500$ & 925 & 4505 & 137 & 10.7 \\
\hline 2 & 267 & $3,999,660$ & 720 & 5555 & 123 & 13.1 \\
\hline 3 & 274 & $5,123,800$ & 785 & 6527 & 128 & 13.0 \\
\hline \multicolumn{7}{|c|}{$21 \mathrm{~h}$ dialysis } \\
\hline 1 & 321 & $2,208,480$ & 820 & 2693 & 72 & 6.4 \\
\hline 2 & 375 & $1,477,500$ & 680 & 2173 & 45 & 5.1 \\
\hline 3 & 394 & $2,458,560$ & 713 & 3448 & 61 & 6.9 \\
\hline
\end{tabular}


binding of ethanol to the lysozyme surface via hydrophobic interactions. This reduces the contacts among the hydrophobic patches and increases the local hydrophilicity due to the exposed $\mathrm{OH}$ groups of the bound ethanol (Liu et al., 2004). In fact, this is the basis of the partial purification of lysozyme in the presence of $30 \%$ ethanol used in this study. Following dialysis, on the other hand, the loss of the activity gained by activation and the 28 $55 \%$ of initial activity suggested that the activation occurred could be reversible and part of the enzyme was destabilized in the presence of 30\% ethanol.

In this study, the average recovery $(59 \%)$ of the partially purified and dialyzed lysozyme is lower than the recovery $(78 \%)$ of the undialyzed partially purified lysozyme obtained by heat denaturation of non lysozyme proteins in hen egg white in the presence of ascorbic acid used as reductant (Chang et al., 2000). However, the average specific activity $(2771 \mathrm{U} / \mathrm{mg})$ of the dialyzed enzyme obtained in this study was almost equal to that of (2996 U/mg) the undialyzed enzyme reported by Chang et al. (2000). Since they found the destabilizing effect of ascorbic acid on lyophilized lysozyme during cold storage, Chang et al. (2000) also applied dialysis after the partial purification. However, the recovery and the specific activity of enzyme following dialysis were not reported by these workers. On the other hand, the average recovery of lysozyme obtained in this study after dialysis was slightly higher than that of $50 \%$ for the undialyzed partially purified lysozyme obtained by the selective precipitation with di-(2-ethylhexyl) sodium sulfosuccinate (AOT), an anionic surfactant, used by Shin et al. (2003).

\subsection{Release of lysozyme from films}

The minimal processing of foods is mostly combined with refrigeration. Thus, the release tests in this study were conducted at $4^{\circ} \mathrm{C}$. For films incorporated with 187,374 and $541 \mathrm{U} / \mathrm{cm}^{2}$ lysozyme, the initial release rates changed between 7 and $9 \mathrm{U} / \mathrm{cm}^{2} / \mathrm{min}$ (Table 2). In films incorporated with $374 \mathrm{U} / \mathrm{cm}^{2}$ lysozyme, the total activity released was close to the incorporated activity. However, in films incorporated with 187 and $541 \mathrm{U} / \mathrm{cm}^{2}$ lysozyme, the total activities released were $32 \%$ and $35 \%$ greater than the incorporated activities in films, respectively. This showed the activation of the lysozyme incorporated into zein films. As observed during partial purification studies, the activation may occur by the effect of ethanol used as film preparation solvent. However, the substantial increases (over $300 \%$ of incorporated activity) of the activities recovered from films incorporated with 708 and $1318 \mathrm{U} / \mathrm{cm}^{2}$ lysozyme suggest that the enzyme concentration may also be effective on the activation (Fig. 1). Also, it appears that the $97 \%$ ethanol used in the film preparation had a stronger activating effect on lysozyme than the $30 \%$ ethanol used in the partial purification medium. At high concentrations, the ethanol is more effective on the protein conformation. In fact, the high concentrations of ethanol may denature or destabilize proteins (Liu et al., 2004). However, it seems that the conformational changes in lysozyme induced by high ethanol concentration pronounced the activation that occurred less intensively at low ethanol concentration. Also, at high ethanol concentrations, the activity gained by activation was stable and not destabilized as occurred in dialysis applied during the partial purification. For example, during release tests of films incorporated with 708 and $1318 \mathrm{U} / \mathrm{cm}^{2}$ lysozyme, the activities lost in the following $24 \mathrm{~h}$ of maximal release in distilled water at $4{ }^{\circ} \mathrm{C}$ (between 360th and 1800th min of release test) were only 25 and $16 \%$, respectively.

For films incorporated with 708 and $1318 \mathrm{U} / \mathrm{cm}^{2}$ lysozyme, the enzyme release rates increased 3-4 fold. Particularly in films incorporated with $1318 \mathrm{U} / \mathrm{cm}^{2}$ enzyme, almost $18 \%$ of the total activity released freed immediately at the first 2.5 th $\mathrm{min}$ of the release test. The rapid release occurred due to the structural changes in films at this high lysozyme concentration and it caused an initial burst in the release curve. At high concentrations, the partially purified enzyme preparation showed very limited solubility in zein film solutions prepared with ethanol. Thus, after casting and drying, the excessive enzyme and the other proteins in enzyme preparation aggregated in the films. The aggregated proteins, formed

Table 2

Some kinetic parameters related to lysozyme release from zein films at $4{ }^{\circ} \mathrm{C}$

\begin{tabular}{|c|c|c|c|c|c|}
\hline No. & $\begin{array}{l}\text { Incorporated lysozyme } \\
\text { activity in films }\left(\mathrm{U} / \mathrm{cm}^{2}\right)\end{array}$ & Release rate $\left(\mathrm{U} / \mathrm{cm}^{2} / \mathrm{min}\right)$ & $\begin{array}{l}\text { Total activity } \\
\text { released }\left(\mathrm{U} / \mathrm{cm}^{2}\right)\end{array}$ & $\begin{array}{l}\text { Activity recovered } \\
\text { from films }(\%)^{\mathrm{d}}\end{array}$ & $\begin{array}{l}\text { Immobilized } \\
\text { activity retained } \\
\text { in films }\left(\mathrm{U} / \mathrm{cm}^{2}\right)^{\mathrm{e}}\end{array}$ \\
\hline 1 & $187(63)^{\mathrm{a}}$ & $9(0-10)^{b}$ & $246 \pm 60(1380)^{\mathrm{c}}$ & 132 & 1.1 \\
\hline 2 & $374(126)$ & $8(0-30)$ & $323 \pm 25(360)$ & 86 & 4.6 \\
\hline 3 & $541(148)$ & $7(0-60)$ & $731 \pm 85(1380)$ & 135 & 11 \\
\hline 4 & $708(244)$ & $27(0-60)$ & $2229 \pm 71(360)$ & 315 & 5 \\
\hline 5 & $1318(455)$ & $29(0-120)$ & $4034 \pm 37(360)$ & 306 & 5 \\
\hline
\end{tabular}

${ }^{\text {a }}$ Lysozyme incorporated into films as $\mu \mathrm{g} / \mathrm{cm}^{2}$.

b Time periods of data used in best fit to calculate initial rates.

${ }^{c}$ Release test periods ( $\mathrm{min}$ ) to achieve maximum activity released.

d (total activity released/incorporated activity) $\times 100$.

e The activities were multiplied by the factor of 10 to obtain comparable results with reaction mixture volumes of soluble activity determination. 




Fig. 1. Release of partially purified lysozyme from different zein films in distilled water at $4{ }^{\circ} \mathrm{C}$.

some semi-transparent light yellow spots on the film surfaces (Fig. 2), are hydrophilic and their greater interaction with water might have caused the increases in enzyme release rates. The aggregates also existed in films incorporated with $541 \mathrm{U} / \mathrm{cm}^{2}$ or less lysozyme, but in these films they were small and rare. Following release tests (for $1800 \mathrm{~min}$ ) the aggregates in the films were hardly perceptible. However, the surfaces of lysozyme incorporated rehydrated films, particularly those incorporated with $1318 \mathrm{U} / \mathrm{cm}^{2}$ lysozyme, become rough. Moreover, following release tests, both control and lysozyme incorporated rehydrated films were elastic and they maintained their integrity. However, when films were stretched, the eroded locations of aggregates in lysozyme incorporated films appeared and films torn at these locations if further stretching was applied.

\subsection{Immobilized lysozyme activity retained in films}

In packaging of foods, the retention of part of the lysozyme in films may be beneficial to maintain the aseptic nature of films and to obtain greater antimicrobial effect at the food contact surfaces. In this study, following $1800 \mathrm{~min}$ release test in distilled water at $4{ }^{\circ} \mathrm{C}$, the immobilized activity retained in films initially containing $187 \mathrm{U} / \mathrm{cm}^{2}$ lysozyme was insignificant (Table 2). However, the immobilized activity of films initially containing 374 and $541 \mathrm{U} / \mathrm{cm}^{2}$ lysozyme increased 4 and 10-fold, respectively (Fig. 3). In films initially containing 708 and $1318 \mathrm{U} / \mathrm{cm}^{2}$ lysozyme, on the other hand, the activity of films dropped. It seems that the deformations occurred because of protein aggregation caused the release of most lysozyme retained by these films. In the literature,

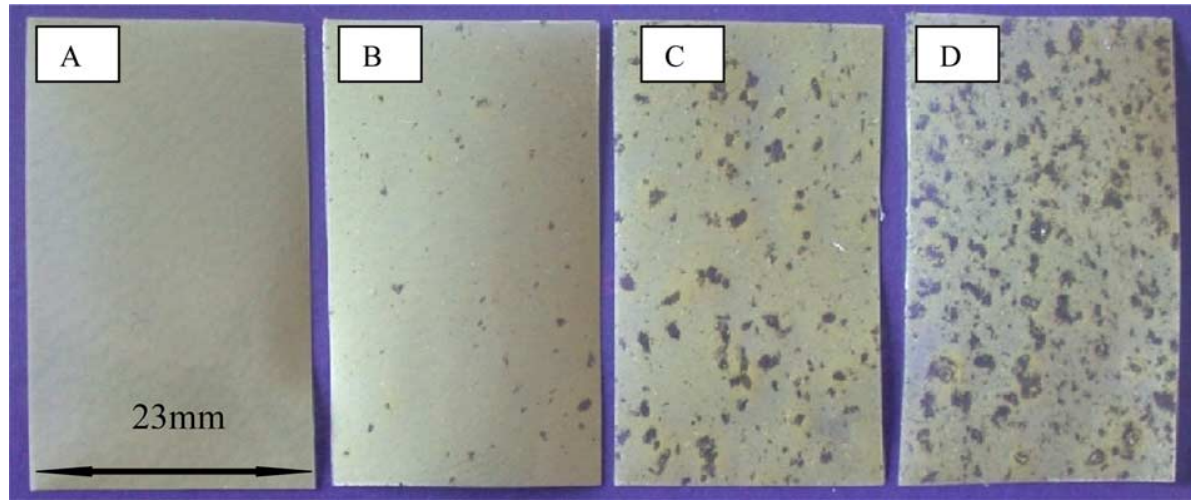

Fig. 2. Photographs of zein films incorporated with partially purified lysozyme (2678 U/mg) [incorporated activities: A, control; B, $187 \mathrm{U} / \mathrm{cm}^{2}$; C, $708 \mathrm{U} / \mathrm{cm}^{2} ; \mathrm{D}, 1318 \mathrm{U} / \mathrm{cm}^{2}$; the background was black to make the spots of light yellow semitransparent protein aggregates visible]. (For interpretation of the references to color in this figure legend, the reader is referred to the web version of this article.) 




Fig. 3. Immobilized lysozyme activity retained in different zein films determined in M. lysodeikticus solutions after 1800 min release test in distilled water at $4{ }^{\circ} \mathrm{C}$.

reports related to affinity of different edible films to lysozyme are scarce. However, Appendini and Hotchkiss (1997), investigated the immobilization of lysozyme on different polymers, determined the high retention of enzyme on cellulose triacetate (CTA) films. These workers incorporated $10-300 \mathrm{mg}$ lysozyme $(3 \times$ crystallized, Sigma Chem. Co.) per g dry weight of CTA used in film preparation and determined $0.6-5.5 \mathrm{U} / \mathrm{cm}^{2}$ activity in $10 \mathrm{~mL} \mathrm{M}$. lysodeikticus cell suspension at $\mathrm{pH} 6.2$ phosphate buffer. Although the lysozyme incorporated CTA films were assayed for immobilized enzyme activity directly, the activities of these films are not significantly greater than those determined in this study for zein films exposed to $1800 \mathrm{~min}$ release test before activity measurements. Thus, as these workers also specified, the measured activity of films does not reflect their lysozyme content but it reflects only the activity of enzyme immobilized at the film surface. Due to its ability to bind on hydrophobic surfaces (Wertz \& Santore, 2002), lysozyme in zein films that are also mainly hydrophobic may be retained by hydrophobic interactions. However, it was reported that in CTA membranes that are also hydrophobic, the lysozyme is absorbed mainly because of the cation-exchange properties of these membranes (Murata $\&$ Tonioka, 1997). Further studies are needed to reveal the binding mechanism of lysozyme on zein films and to show the contribution of immobilized lysozyme activity to their antimicrobial effect.

\subsection{Stability of partially purified lysozyme in lyophilized form}

The lysozyme is generally known with its high structural stability. However, Chang et al. (2000) found that
Table 3

Stability of partially purified lysozyme in lyophilized form and in zein films

\begin{tabular}{lll}
\hline Storage time (days) & \multicolumn{2}{l}{ Activity } \\
\cline { 2 - 3 } & $\mathrm{U} / \mathrm{mg}$ & $\%$ Initial activity \\
\hline Partially purified lysozyme & in lyophilized form stored at $-18^{\circ} \mathrm{C}$ \\
Batch \#1 & \\
0 & $3345 \pm 166$ & 100 \\
10 & $3658 \pm 70$ & 109 \\
80 & $3521 \pm 128$ & 105 \\
Batch \#2 & \\
0 & $2900 \pm 325$ & 100 \\
24 & $2979 \pm 234$ & 103 \\
137 & $3179 \pm 236$ & 110 \\
240 & $2941 \pm 71$ & 101 \\
Batch \#3 & & \\
0 & $3351 \pm 501$ & 100 \\
45 & $3374 \pm 300$ & 101 \\
& & \\
& $\mathrm{U} / \mathrm{cm}^{2}$ & $\%$ Initial activity \\
\hline Partially purified lysozyme in zein films ${ }^{\mathrm{a}}$ stored at $4^{\circ} \mathrm{C}$ \\
0 & $382 \pm 87$ & 100 \\
15 & $321 \pm 56$ & 84 \\
45 & $378 \pm 81$ & 99 \\
120 & $417 \pm 87$ & 109 \\
\hline
\end{tabular}

${ }^{a}$ Incorporated with $374 \mathrm{U} / \mathrm{cm}^{2}$ lysozyme and $180 \mu \mathrm{g} / \mathrm{cm}^{2}$ disodium EDTA.

the partially purified lyophilized lysozyme is not stable during cold storage without dialysis. These workers attributed the instability of undialyzed partially purified lysozyme to the inhibitory effects of reductants such as ascorbic acid, cysteine or cystine used during enzyme purification. The activities of different batches of lyophilized lysozymes used in this study varied between 2900 and $3351 \mathrm{U} / \mathrm{mg}$ and the enzymes showed a very high stability in lyophilized form at $-18^{\circ} \mathrm{C}$ (Table 3). For example, the initial activity of enzyme obtained in batch \#2 unchanged at the end of 8 months storage. These results clearly showed that the partially purified lysozyme obtained in this study may be a suitable source for food industry.

\subsection{Stability of partially purified lysozyme in zein films}

In zein films incorporated with partially purified lysozyme and disodium EDTA and cold stored at $4{ }^{\circ} \mathrm{C}$, the enzyme lost almost $15 \%$ of its activity determined in release tests by 15 days storage. However, in the following months of storage the released activity increased almost to the level of activity initially released from the films. The importance of some hydrophobic groups such as tryptophan-108 in maintaining lysozyme activity and conformational stability has been shown recently (Inoue et al., 1992). Thus, the stability of the enzyme in zein films may be related with the protective effect of hydrophobic environment in 
Table 4

Antimicrobial effects of partially purified lysozyme and/or disodium EDTA incorporated zein films

\begin{tabular}{|c|c|c|c|c|c|}
\hline \multicolumn{2}{|c|}{$\begin{array}{l}\text { Incorporated activity and } \\
\text { concentrations in films }\end{array}$} & \multicolumn{2}{|c|}{$\begin{array}{l}\text { Incorporated activity and } \\
\text { concentrations in discs }\end{array}$} & \multirow{2}{*}{$\begin{array}{l}\text { Number of fully formed } \\
\text { (ffz), partially formed (pfz) or } \\
\text { negative (nz) zones }\end{array}$} & \multirow[t]{2}{*}{$\begin{array}{l}\text { Average area of } \\
\text { fully formed zones }\left(\mathrm{cm}^{2}\right)\end{array}$} \\
\hline Lysozyme $\left(\mathrm{U} / \mathrm{cm}^{2}\right)$ & $\begin{array}{l}\text { Disodium } \\
\operatorname{EDTA}\left(\mu \mathrm{g} / \mathrm{cm}^{2}\right)\end{array}$ & Lysozyme (U) & $\begin{array}{l}\text { Disodium } \\
\text { EDTA }(\mu \mathrm{g})\end{array}$ & & \\
\hline \multicolumn{6}{|l|}{ B. subtilis } \\
\hline- & - & - & - & Controls (3 nz) & 0 \\
\hline $374(111)^{\mathrm{a}, \mathrm{b}}$ & - & $238(71)$ & - & $1 \mathrm{pfz} / 8 \mathrm{ffz}$ & 1.65 \\
\hline $748(260)^{\mathrm{c}}$ & - & $476(165)$ & - & $3 \mathrm{nz} / 6 \mathrm{ffz}$ & 1.60 \\
\hline $1467(510)^{\mathrm{c}}$ & - & $933(324)$ & - & $4 \mathrm{nz} / 5 \mathrm{ffz}$ & 2.24 \\
\hline \multicolumn{6}{|l|}{ E. coli } \\
\hline- & - & - & - & Controls (3 nz) & 0 \\
\hline- & 180 & - & 115 & $4 \mathrm{nz} / 5 \mathrm{ffz}$ & 0.63 \\
\hline $374(111)^{b}$ & 180 & $238(71)$ & 115 & $3 \mathrm{pfz} / 6 \mathrm{ffz}$ & 0.59 \\
\hline $748(260)^{\mathrm{c}}$ & 180 & $476(165)$ & 115 & $2 \mathrm{pfz} / 7 \mathrm{ffz}$ & 1.32 \\
\hline $1524(530)^{\mathrm{c}}$ & 180 & $969(337)$ & 115 & $3 \mathrm{nz} / 6 \mathrm{ffz}$ & 1.29 \\
\hline \multicolumn{6}{|l|}{ L. plantarum } \\
\hline- & - & - & - & Controls (3 nz) & 0 \\
\hline $748(204)^{\mathrm{d}}$ & - & $476(130)$ & - & $9 \mathrm{nz}$ & 0 \\
\hline $1467(401)^{\mathrm{d}}$ & - & $933(255)$ & - & $9 \mathrm{ffz}$ & 1.17 \\
\hline
\end{tabular}

Activities of lyophilized lysozymes: ${ }^{\mathrm{b}} 3382 \mathrm{U} / \mathrm{mg},{ }^{\mathrm{c}} 2876 \mathrm{U} / \mathrm{mg},{ }^{\mathrm{d}} 3658 \mathrm{U} / \mathrm{mg}$ and ${ }^{\mathrm{e}}$ Lysozyme in discs as $\mu \mathrm{g}$.

a Lysozyme incorporated into films as $\mu \mathrm{g} / \mathrm{cm}^{2}$.

these films. The results of this study showed also the lack of any inhibitory effect of ingredients used in zein film preparation. Thus, it is clear that the ready to use pre-cast zein films incorporated with lysozyme and disodium EDTA may be supplied commercially for packaging applications.

\subsection{Antimicrobial activity of films}

The zein films incorporated with partially purified lysozyme showed good antimicrobial activity on B. subtilis (Table 4). For films incorporated with 374 and $748 \mathrm{U} / \mathrm{cm}^{2}$ lysozyme, the areas of fully formed zones against this microorganism were almost same. However, in films incorporated with $748 \mathrm{U} / \mathrm{cm}^{2}$ lysozyme, 3 of the 9 discs tested on B. subtilis were negative (no clear zones were observed). The average area of the fully formed zones increased by increasing the concentration of incorporated lysozyme in films to $1467 \mathrm{U} / \mathrm{cm}^{2}$. However, this caused a further increase in the number of negative discs (4/9). This result suggests that the distribution of partially purified lysozyme in zein films becomes less homogenous at high concentrations. This occurred possibly because of the increased sizes of hydrophilic aggregates rich in partially purified lysozyme and formation of some locations on film surface with insufficient lysozyme activity. In tests on E. coli, incorporation of $374 \mathrm{U} / \mathrm{cm}^{2}$ lysozyme and $180 \mu \mathrm{g} / \mathrm{cm}^{2}$ disodium EDTA into zein films did not show strong antimicrobial activity. At these lysozyme and disodium EDTA concentrations, the average area of fully formed zones of films was almost same with that of fully formed zones of films incorporated with only disodium EDTA. However, in lysozyme containing films, partially formed zones were observed instead of negative discs observed for films containing only disodium EDTA. On the other hand, in films incorporated with $748 \mathrm{U} / \mathrm{cm}^{2}$ lysozyme and $180 \mu \mathrm{g} / \mathrm{cm}^{2}$ disodium EDTA, zone formation ( 2 partially formed and 7 fully formed) was observed for all discs tested with more than a 2-fold increase in the average area of fully formed zones (Fig. 4). This result shows that at these concentrations the combinational use of both agents caused a more homogenous distribution and stronger antimicrobial effect. Further increase of incorporated lysozyme concentration while disodium EDTA concentration was constant did not increase the

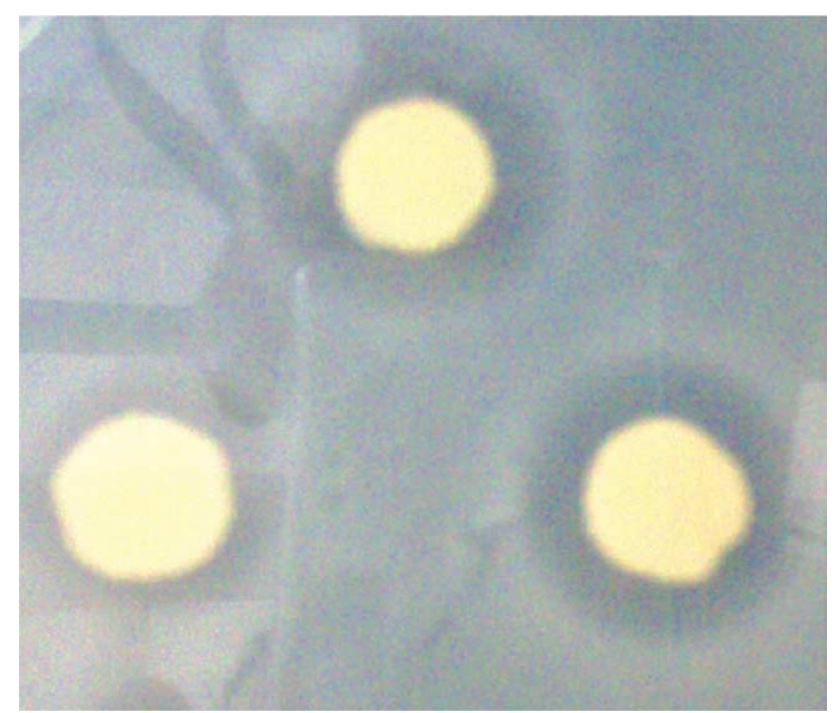

Fig. 4. Antimicrobial effect of lysozyme and disodium EDTA incorporated zein films on E. coli (incorporated lysozyme activity of discs: 476 $\mathrm{U}$; disodium EDTA concentration of discs: $115 \mu \mathrm{g}$ ). 
zone area. Also, this again caused the formation of some negative discs (in 3/9 discs tested).

The test of partially purified lysozyme on $L$. plantarum, on the other hand, showed the resistance of lactic acid bacteria to lysozme. In films incorporated with $748 \mathrm{U} / \mathrm{cm}^{2}$ lysozyme, no zones formed in petri dishes. In films incorporated with $1467 \mathrm{U} / \mathrm{cm}^{2}$ lysozyme, on the other hand, fully formed zones were observed for all discs tested. However, these zones were smaller than those obtained for B. subtilis. For L. plantarum, the minimum inhibitory concentration of commercial lysozyme (Sigma Chem. Co.) incorporated into zein films was reported as $50-100 \mu \mathrm{g}$ per $0.86 \mathrm{~mm}$ diameter discs (Padgett et al., 1998). In our discs which showed antimicrobial activity on L. plantarum, there was almost $255 \mu \mathrm{g}$ (933 U) partially purified lysozyme. Although the commercial lysozyme activity (reported as $50,000 \mathrm{U} / \mathrm{mg}$ by Sigma) is almost 16-folds higher than that of average activity of different batches of partially purified lysozyme used in this study, there is only $2.5-5$-fold difference between the effective concentrations of two lysozymes in zein films tested on $L$. plantarum. In this study, the recovery of activity in films incorporated with 708 and $1318 \mathrm{U} / \mathrm{cm}^{2}$ lysozyme was almost $300 \%$ (Table 2 ). Thus, it appears that the effectiveness of the partially purified lysozyme on $L$. plantarum was due to activation. Further studies should be conducted to compare the antimicrobial activities of pure and partially pure lysozymes under the same conditions on different bacteria.

\section{Conclusions}

Partially purified lysozyme from hen egg white showed good storage stability in lyophilized form and in zein films containing disodium EDTA. This result shows that the ready to use pre-cast antimicrobial zein films may be supplied commercially for packaging applications. The partially purified enzyme incorporated into zein films showed antimicrobial activity on different bacteria including $B$. subtilis and L. plantarum. Also, films obtained by combination of lysozyme with disodium EDTA showed antimicrobial effect on $E$. coli. The activation of partially purified lysozyme in zein films brings the advantage of obtaining an antimicrobial effect in zein films with low initial lysozyme activities. The low solubility of partially purified enzyme preparation in zein films, on the other hand, causes the formation of protein aggregates in zein films. Thus, some additional edible ingredients such as proteins with emulsifying activity may also be employed to minimize structural changes and to obtain more uniform antimicrobial zein films. Further tests are now continuing in our laboratory to improve the structural aspects of partially purified lysozyme incorporated zein films and to test the obtained films on different foods.

\section{Acknowledgment}

This project (MISAG \#221) was funded by the TÜBİTAK (Scientific and Technical Research Council of Turkey).

\section{References}

Appendini, P., \& Hotchkiss, J. H. (1997). Immobilization of lysozyme on food contact polymers as potential antimicrobial films. Packaging Technology and Science, 10, 271-279.

Appendini, P., \& Hotchkiss, J. H. (2002). Review of antimicrobial food packaging. Innovative Food Science and Emerging Technologies, 3, 113-126.

Bonincontro, A., De Francesco, A., Matzeu, M., Onori, G., \& Santucci, A. (1997). Conformational changes of lysozyme in water-ethanol mixtures. Colloids and Surfaces B: Biointerfaces, 10, 105-111.

Branen, J. K., \& Davidson, P. M. (2004). Enhancement of nisin, lysozyme, and monolaurin antimicrobial activities by ethylenediaminetetraacetic acid and lactoferrin. International Journal of Food Microbiology, 90, 63-74.

Chang, H., Yang, C., \& Chang, Y. (2000). Rapid separation of lysozyme from chicken egg white by reductants and thermal treatment. Journal of Agricultural and Food Chemistry, 48(2), 161-164.

Cha, D. S., Choi, J. H., Chinnan, M. S., \& Park, H. J. (2002). Antimicrobial films based on Na-alginate and $\kappa$-carrageenan. Lebensmittel Wissenschaft und Technologie, 35(8), 715-719.

De Roever, C. (1998). Microbiological safety evaluations and recommendations on fresh produce. Food Control, 9(6), 321-347.

Dawson, P., Hoffman, K., \& Han, I. (2000). Biocide-impregnated food films to inhibit food pathogens. In Second NSF international conference on food safety, Savannah, GA (pp. 11-13).

Han, J. H. (2000). Antimicrobial food packaging. Food Technology, 54(3), 56-65.

Harris, D. A. (1987). Spectrophotometric assays. In D. A. Harris \& C. L. Bashford (Eds.), Spectrophotometry and spectrofluorometry (pp. 59-60). Oxford: I.R.L. Press.

Herald, T. J., Hachmeister, K. A., Huang, S., \& Bowers, J. R. (1996). Corn zein packaging materials for cooked turkey. Journal of Food Science, 61(2), 415-418.

Hoffman, KL., Han, I. Y., \& Dawson, P. L. (2001). Antimicrobial effects of corn zein films impregnated with nisin, lauric acid, and EDTA. Journal of Food Protection, 64(6), 885-889.

Inoue, M., Yamada, H., Yasukochi, T., Kuroki, R., Miki, T., Horiuchi, T., et al. (1992). Multiple role of hydrophobicity of tryptophan-108 in chicken lysozyme: Structural stability, saccharide binding ability, and abnormal $\mathrm{p} K_{\mathrm{a}}$ of glutamic acid-35. Biochemistry, 31(24), 5545-5553.

Janes, M. E., Kooshesh, S., \& Johnson, M. G. (2002). Control of Listeria monocytogenes on the surface of refrigerated, ready-to-eat chicken coated with edible zein film coatings containing nisin and/ or calcium propionate. Journal of Food Science, 67(7), 2754-2757.

Jiang, C. M, Wang, M. C., Chang, W. H., \& Chang, H. M. (2001). Isolation of lysozyme from hen egg albumen by alcohol-insoluble crosslinked pea pod solid ion-exchange chromatography. Journal of Food Science, 66(8), 1089-1092.

Judge, R., Forsythe, E. L., \& Pusey, M. L. (1998). The effect of protein impurities on lysozyme crystal growth. Biotechnology and Bioengineering, 59(6), 776-785.

Labuza, T. P., \& Breene, W. M. (1989). Applications of "active packaging" for improvement of shelf-life and nutritional quality of fresh and extended shelf-life foods. Journal of Food Processing and Preservation, 13, 1-69.

Liu, W., Bratko, D., Prausnitz, J. M., \& Blanch, H. W. (2004). Effect of alcohols on aqueous lysozyme-lysozyme interactions from static light-scattering measurements. Biophysical Chemistry, 107, 289-298. 
Murata, T., \& Tonioka, A. (1997). Interfacial state change of cellulose triacetate membrane by adsorption of polyelectrolyte. Journal of Colloid and Interface Science, 192, 26-36.

Padgett, T., Han, I. Y., \& Dawson, P. L. (1998). Incorporation of foodgrade antimicrobial compounds into biodegradable packaging films. Journal of Food Protection, 61(10), 1330-1335.

Quintavalla, S., \& Vicini, L. (2002). Antimicrobial food packaging in meat industry. Meat Science, 62, 373-380.

Rakotonirainy, A. M., Wang, Q., \& Padua, G. W. (2001). Evaluation of zein films as modified atmosphere packaging for fresh broccoli. Journal of Food Science, 66(8), 1108-1111.
Shin, Y. O., Rodil, E., \& Vera, J. H. (2003). Selective preparation of lysozyme from egg white using AOT. Journal of Food Science, 68(2), 595-599.

Suppakul, P., Miltz, J., Sonneveld, K., \& Bigger, S. W. (2003). Active packaging technologies with an emphasis on antimicrobial packaging and its applications. Journal of Food Science, 68(2), 408-420.

Teerakarn, A., Hirt, D. E., Acton, J. C., Rieck, J. R., \& Dawson, P. L. (2002). Nisin diffusion in protein films: effects of film type and temperature. Journal of Food Science, 67(8), 3019-3025.

Wertz, C. F., \& Santore, M. M. (2002). Adsorption and reorientation kinetics of lysozyme on hydrophobic surfaces. Langmuir, 18(4), 1190-1199. 